Check for updates

Cite this: RSC Adv., 2019, 9, 11530

Received 24th January 2019

Accepted 1st April 2019

DOI: $10.1039 / c 9 r a 00627 c$

rsc.li/rsc-advances

\title{
Kinetic inhibition effect of Type I and III antifreeze proteins on unidirectional tetrahydrofuran hydrate crystal growth
}

\author{
Michihiro Muraoka, (D) * Michika Ohtake and Yoshitaka Yamamoto
}

Experiments were performed to evaluate the kinetic inhibition effect of Type I and Type III antifreeze proteins (AFPs), polyvinyl alcohol (PVA) and polyvinylpyrrolidone (PVP) on the growth of tetrahydrofuran (THF) clathrate hydrate crystals using the unidirectional growth technique. The crystal growth interface shifted under an applied temperature gradient over a given time. Type I AFP was the most effective kinetic inhibitor, followed by PVP, Type III AFP and PVA. The morphology of the THF hydrate was affected significantly by the concentration of Type I AFP. At low concentrations of Type I AFP, a large hexagonal plate-like crystal formed. At high concentrations, the growth interface became relatively flat. Conversely, at low concentrations of Type III AFP, the morphology of the THF hydrate crystal was unaffected by the additive.

\section{Introduction}

Gas hydrates are ice-like crystalline solids that trap guest molecules of gas within the cells formed by the hydrogen bonds of water. ${ }^{1}$

The formation of natural gas hydrate plugs during petroleum extraction and transportation has been a serious problem for many years. ${ }^{2}$ Thermodynamic inhibitors (THIs) such as methanol are often used to inhibit the formation of hydrates in pipelines. Such inhibitors shift the equilibrium state of the gas hydrates to a higher pressure and lower temperature. However, high doping is necessary to prevent hydrate formation. Novel inhibitors called kinetic hydrate inhibitors (KHIs) have been developed, requiring much less doping to effectively inhibit hydrate formation. KHIs primarily act by delaying the nucleation and slowing the growth rate of the hydrate. ${ }^{3}$ Evaluating and comparing the performance of KHIs and THIs is very difficult.

Lederhos et al. evaluated kinetic inhibitors among 1500 chemicals. ${ }^{4}$ They used 12 test tubes (rocking cell) filled with a tetrahydrofuran (THF)/water solution, and each tube contained a stainless-steel ball. They screened KHIs by monitoring the time period for which the ball movement was blocked by the formed hydrate.

Larsen et al. evaluated KHIs using single crystals of THF and ethylene oxide (EO) hydrate. ${ }^{5}$ THF and EO hydrate have structure II and I, respectively. Authors measured the minimum concentration required to obtain complete inhibition of crystal

Research Institute of Energy Frontier, National Institute of Advanced Industrial Science and Technology (AIST), Onogawa, Tsukuba, Ibaraki 305-8569, Japan. E-mail: m-muraoka@aist.go.jp; Fax: +81 29861 8765; Tel: +81298612841 growth $v s$. the degree of super cooling. They also reported that the morphology of THF hydrate changed from octahedra to 2dimensional hexagonal plates owing to the KHIs effect.

Anderson et al. developed a procedure named the crystal growth inhibition (CGI) method for evaluating KHI performance. ${ }^{6}$ In the CGI method, KHIs are tested over several cycles of hydrate growth and melting cycles with the repeated system cooling and heating being maintained at a constant rate. The rocking-cell system is also used for the efficient evaluation of KHI performance. Chua et al. used five high-pressure steel rocking cells. ${ }^{7}$

Successful inhibitors were found by trial and error. ${ }^{4}$ On the contrary, some of the current KHI designs were inspired by research on antifreeze proteins (AFPs) ${ }^{8}$ that suppress the growth rate of ice crystals and change the crystal morphology. The inhibiting action of AFPs on ice recrystallisation and growth helps living organisms survive in subfreezing environments. ${ }^{9}$

Type I AFP was initially discovered in the blood plasma of a fish, the winter flounder; ${ }^{10}$ it has a simple $\alpha$-helical structure. ${ }^{\mathbf{1 1}}$ At low concentrations, it adsorbs on the bipyramidal plane surfaces of ice crystals, ${ }^{12}$ whereas at high concentrations, it adsorbs on all orientation surfaces of ice crystals, including on the basal planes.

Type III AFP, a globular protein, was first discovered in an ocean pout (Zoarcidae or eelpouts); ${ }^{\mathbf{1 3}, \mathbf{1 4}}$ it adsorbs on the prism and pyramidal planes of ice crystals. ${ }^{15}$

Zeng et al. tested the effects of Type I AFP and another AFP Type extracted from insects to inhibit the growth of (THF) hydrate. The results showed that both AFPs affect the morphology and inhibit nucleation of THF hydrate crystal. ${ }^{16}$ In addition, they showed that both AFPs eliminate the memory effect. 
Zeng et al. tested the effects of Type I AFP to inhibit the growth of methane hydrate and propane hydrate. ${ }^{17}$ Both nucleation and crystal growth were inhibited using AFP.

Daraboina et al. studied the inhibition effects of TYPE III AFP and PVP for gas hydrate. ${ }^{18-20}$ Their results showed that AFP III and PVP delayed the onset of hydrate nucleation. ${ }^{18}$ Their results also showed that AFP I was a more effective than either PVP or TYPE III AFP. ${ }^{19}$

Polyvinyl alcohol (PVA) is a water-soluble polymer with hydroxyl groups exhibiting a multiple-stranded, helical structure when dissolved in water. Inada et al. and Wang et al. found that PVA inhibits the growth of ice. ${ }^{21,22}$ Budke and Koop and Inada et al. reported that PVA inhibits the recrystallisation of ice. ${ }^{23,24} \mathrm{Du}$ et al. found that the adhesion force of THF hydrate particle is weakened by the addition of PVA. ${ }^{25}$

DuQuesnay et al. developed a novel gas hydrate reactor that enables the observation of the morphology of gas hydrate formed under a temperature gradient. ${ }^{26}$ Udegbuman et al. ${ }^{27}$ used the same reactor to evaluate AFPs from fish, beetle, and grass. They reported the relationship between film hydrate velocity and super cooling.

In most of the KHI performance evaluation experiments, gas hydrate was formed by stirring gas and water in a high-pressure reactor, or THF hydrate forms in a rocking cell. These types of experiments cannot separate the inhibition effect of growth and nucleation. The data exclusively focused on only evaluating the growth inhibition effect, which is scarce. We consider that simplified experimental data is necessary to clarify the $\mathrm{KHI}$ mechanism.

In a previous publication, we proposed a simple method for evaluating KHI performance with a unidirectional growth apparatus. $^{28}$ We measured the degree of supercooling while controlling the rate of crystal growth to evaluate the antifreeze performance of polyvinylpyrrolidone (PVP). This technique eliminates nucleation and solely evaluates growth inhibition effect. It allows for easy quantification of the inhibition performance and the observation of interfacial phenomena during the hydrate crystal growth.

In this study, we evaluate the kinetic inhibition performance of Type I AFP, Type III AFP, PVA and PVP on the growth of THF clathrate hydrate crystals using the unidirectional growth technique. In addition, we analyse the differences in the inhibitory action of Type I and Type III AFP.

\section{Experimental methods}

A stoichiometric THF-water solution (1:17) prepared from dehydrated stabiliser-free THF (99.5 wt\% purity, Kanto Chemical Co., Japan) and ultrapure water $(18.2 \mathrm{M} \Omega \times \mathrm{cm}$ resistivity) was used for the tests. High-purity Type I AFP extracted from the winter flounder (average molecular weight $=3200$, Nichirei Co., Japan), high-purity Type III AFP from the ocean pout or eelpout (average molecular weight $=6700$, Nichirei Co., Japan), PVA (98\% purity, average molecular weight $=16$ 000, Kanto Chemical Co., Japan) and PVP (K-90, average molecular weight $=$ 1200 000, Junsei Chemical Co. Ltd., Japan) were added to the THF-water solution for testing.
The present study employed the same experimental methods that we reported previously; ${ }^{28}$ we summarised the setup as follows.

The sample cell comprised two glass plates $(26 \times 76 \times 1$ $\mathrm{mm}$ ) and rubber spacers. Two thermocouples (Type T, 01-T, Ninomiya Electric Wire Co. Ltd., Japan) were inserted between the rubber spacer and the glass plate. The calibrated thermocouples are accurate within $0.2{ }^{\circ} \mathrm{C}$. The measurement positions of the thermocouples were $\sim 5 \mathrm{~mm}$ (no. 1) and $15 \mathrm{~mm}$ (no. 2) from the right inner edge of the cell.

The unidirectional growth apparatus generates a constant temperature gradient $G$ across the sample cell via a set of cold and hot copper blocks. The sample cell was placed on the cold and hot blocks. The hot block was held at a temperature above the equilibrium temperature $T_{\text {eq }}$ while the cold block was held at a temperature below $T_{\text {eq. }}$. The thermocouple measurements were recorded by a data logger (midi Logger GL840, Graphtec Co., Japan). The nucleation of hydrate crystals was initiated by cooling the colder side of the capillary using a cold spray (134a QREI, QRA -S481, Sunhayato Co., Japan). Then, an initial growth interface of an extra $0.3 \mathrm{~mm}$ was formed to ensure a flat interface. Next, excess hydrates were melted by moving the sample cell slightly towards the hot block, the cell was kept still for $2 \mathrm{~h}$. After these preparations, the sample cell was moved using a pulse motor at constant velocity $(V)$ towards the colder block. The cell was moved a total distance of $25 \mathrm{~mm}$ towards the colder block in each experiment.

The optical system comprised an optical zoom lens (VZM 600I, Edmund optics) and a CCD camera (EO-1312M, Edmund optics). The CCD camera images were recorded on a personal computer running on the Windows operating system (Windows 8).

The KHI concentration $(c)$ and $V$ were the independent variables in this study.

\section{Results and discussion}

Fig. 1 shows sequential images of the hydrate growth interface of THF aqueous solution $\left(\mathrm{THF}-17 \mathrm{H}_{2} \mathrm{O}\right)$ with Type I AFP $(c=$ $0.5 \mathrm{wt} \%$ and $\left.V=1 \mu \mathrm{m} \mathrm{s}^{-1}\right)$. The time elapsed from the start of the crystal growth shown in Fig. 1 are (a) $t=0 \mathrm{~min}$, (b) $t=$ $13 \mathrm{~min},(\mathrm{c}) t=125 \mathrm{~min}$, and (d) $t=231 \mathrm{~min}$. The single arrow in each figure indicates the position of the crystal growth interface. On observing the details, the microscopic interface shape comprises many fine needles. From $t=0$ to $t=13 \mathrm{~min}$, the growth interface gradually shifted toward the cold block as it was moved through the temperature gradient. After $125 \mathrm{~min}$ [Fig. 1(c)], the interface position was constant, indicating the system was steady state. At $t=231 \mathrm{~min}$ [Fig. 1(d)], the growth interface reached the thermocouple tip (no. 2), located at $15 \mathrm{~mm}$ from the right edge of the cell. The length of doubleheaded arrow $\Delta x_{\mathrm{i}}(t)$ [Fig. 1(c)] shows the distance between the crystal growth interface position at a certain time and its position at the beginning of the growth $(t=0)$. The values of $\Delta x_{\mathrm{i}}$ were obtained by averaging 10 measurements at different positions along the interface. " $\Delta x_{\mathrm{i}}$ " indicates the excess of supercooling caused by KHI doping, relative to the supercooling that occurs in a simple THF aqueous solution. From 
measurements of $\Delta x_{\mathrm{i}}(t)$ at steady state, we can calculate the supercooling due to the KHI additive $\left(\Delta T_{\mathrm{i}}\right){ }^{28}$

In our previous study, we calculated the temperatures at each position of the sample cell based on the temperature gradient, and the distance from each thermo-block. $\Delta T_{\mathrm{i}}$ was calculated using the simple formula in (1):

$$
\Delta T_{\mathrm{i}}=G_{\mathrm{ave}} \Delta x_{\mathrm{i}}
$$

where $G_{\text {ave }}$ was the linear temperature gradient and was calculated as $G_{\text {ave }}=\left(G_{1}+G_{2}\right) / 2$, where $G_{1}$ and $G_{2}$ were the temperature gradients recorded by thermocouples no. 1 and 2,

(a)

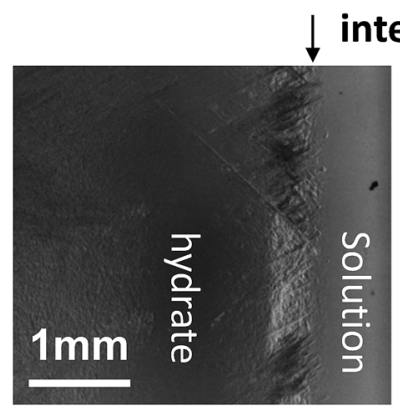

(b)

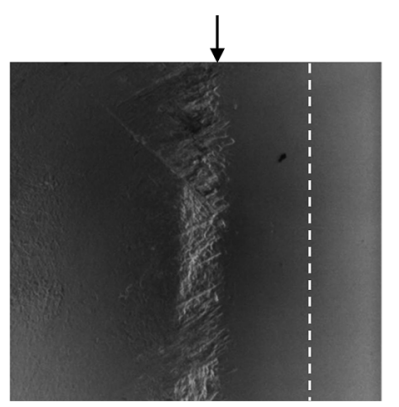

(c)

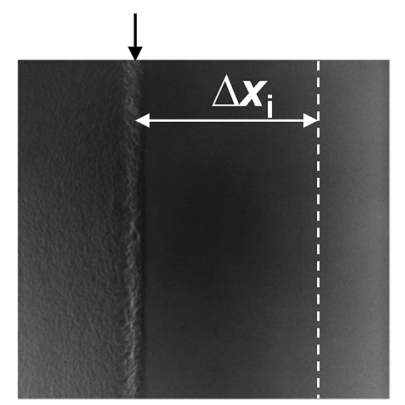

(d)

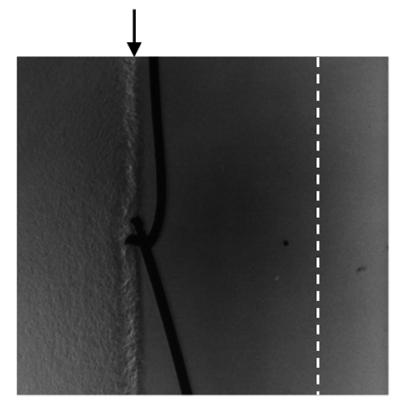

Fig. 1 Sequential images of the growth interface of THF hydrate with the additive Type I AFP at a concentration of $c=0.5 \mathrm{wt} \%$ and $V=1 \mu \mathrm{m}$ $\mathrm{s}^{-1}$. The growth times are (a) $t=0 \mathrm{~min}$, (b) $t=13 \mathrm{~min}$, (c) $t=125 \mathrm{~min}$ and (d) $t=231 \mathrm{~min}$. respectively. In the present experiments, $G$ is approximately $1.9^{\circ} \mathrm{C} \mathrm{mm}^{-1}$ in all experimental runs. To check the accuracy of this method, we compare the values of $\Delta T_{\mathrm{i}}$ estimated from Formula (1) and those measured directly from the thermocouple tips inside the cell.

In the cases of THF aqueous solutions containing PVP or PVA or TYPE III AFP, the calculated and directly measured crystal growth interface temperatures agree well within the error of the measurements. However, in the case of AFP Type I solutions, the two interface temperatures do not agree.

Fig. 2(a) shows the relation between $\Delta x_{\mathrm{i}}(t)$ and $x_{\text {cell }}(t)$ (the distance the sample cell moved) for Type I AFP $\left(V=1 \mu \mathrm{m} \mathrm{s}^{-1}, c\right.$ $=0.5 \mathrm{wt} \%)$; the dotted line represents the hypothetical line of $\Delta x_{\mathrm{i}}=x_{\text {cell }}$. If the position of the growth interface relative to the cell would remain constant (i.e. the hydrate does not grow after $t$ $=0$ ), the interface behavior would develop according to the linear relationship shown by the dotted line. However, the results show that as $x_{\text {cell }}$ increases, $\Delta x_{\mathrm{i}}$ also increases within the first $5 \mathrm{~mm}$ of the cell motion. Beyond $x_{\text {cell }}=5 \mathrm{~mm}, \Delta x_{\mathrm{i}}$ remains almost constant in all cases. Fig. 2(b) plots the degree of supercooling at the growth interface, $\Delta T_{\mathrm{i}}$, against $x_{\text {cell }}$.

The white and black circles in Fig. 2(b) indicate the directly measured degree of supercooling and the values as calculated from Formula (1), respectively. The calculated values of $\Delta T_{\mathrm{i}}$ and
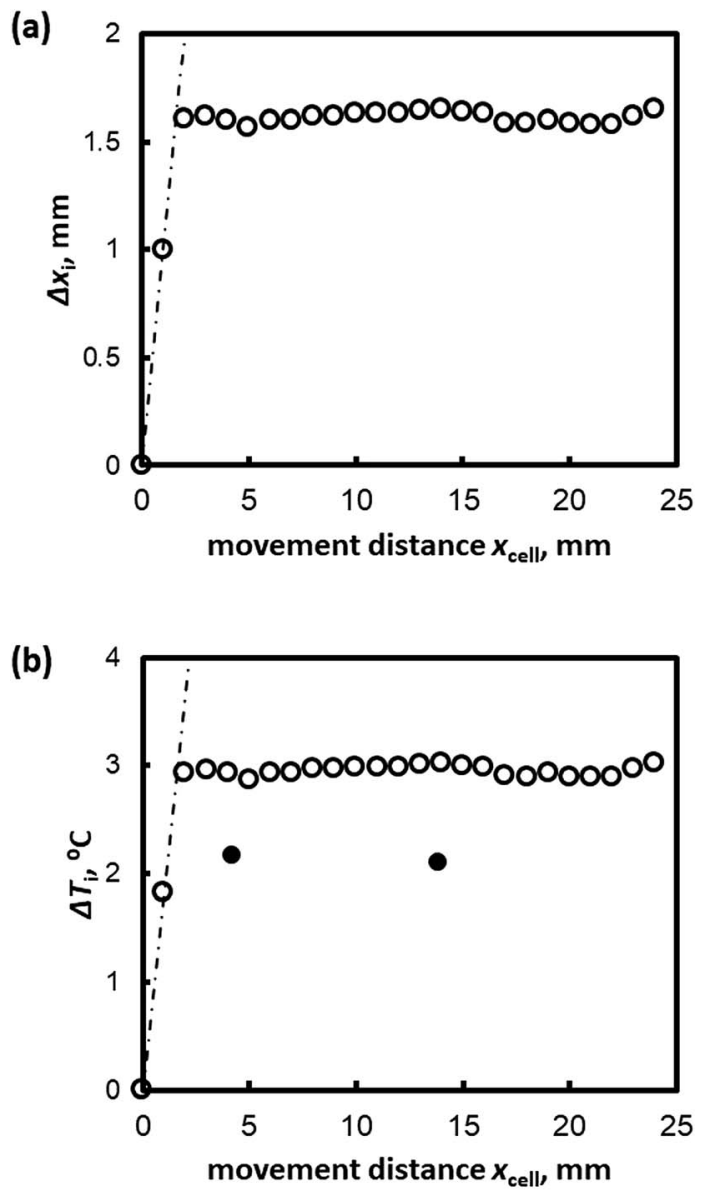

Fig. 2 (a) $\Delta x_{i}$ and (b) $\Delta T_{i}$ plotted against the distance moved by the sample cell, $x_{\text {cell }}(t)$, for $V=1 \mu \mathrm{m} \mathrm{s}^{-1}$ for Type I AFP $c=1.0 \mathrm{wt} \%$. 


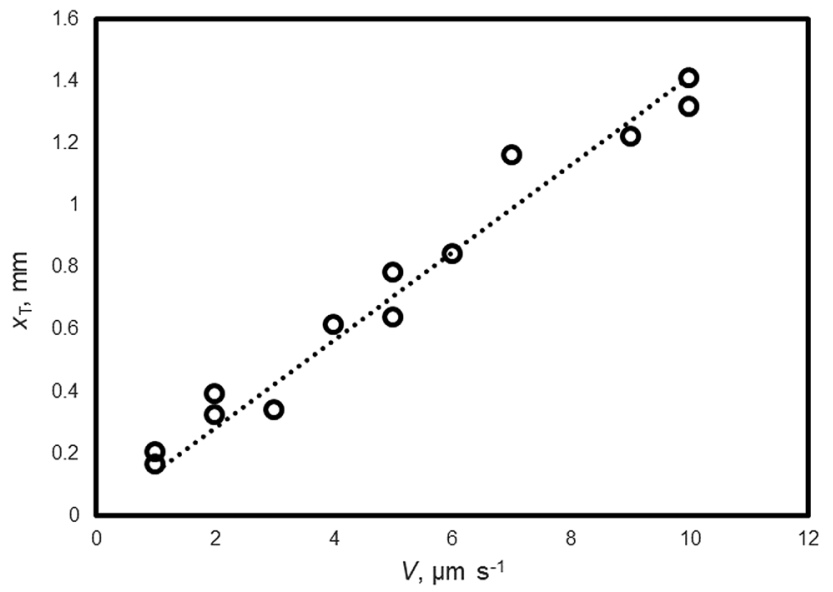

Fig. 3 The relationship between $V$ and $x_{T}$ of THF hydrate (no additive).

the measurements at the thermocouple tip differ; Formula (1) overestimates $\Delta T_{\mathrm{i}}$ in the case of Type I AFP.

Celik et al. showed that ice can be superheated in AFP solutions under isothermal conditions. ${ }^{29}$ Knight and Devries developed a schematic model that explains how AFP bound to the ice-crystal surface allows superheating. ${ }^{30}$

The observed disagreement between the calculated values of $\Delta T_{\mathrm{i}}$ from Formula (1) and the measured values may be explained by superheating at the initial growth interface. The initial interface is prepared by melting $0.3 \mathrm{~mm}$ of hydrate. Normally, the temperature of the initial interface is at the melting temperature of the simple THF aqueous solution (4.4 $\left.{ }^{\circ} \mathrm{C}\right)$. However, the initial interface is in contact with the AFP solution in this case, which should cause superheating of the THF hydrate crystals.

To determine the growth interface temperature, the formula $\Delta T=G \Delta x$ is normally implemented. However, since AFP is used in the experiment, Formula (2) should be applied instead.

$$
\Delta T=G \Delta x-\Delta T_{\mathrm{s}}
$$

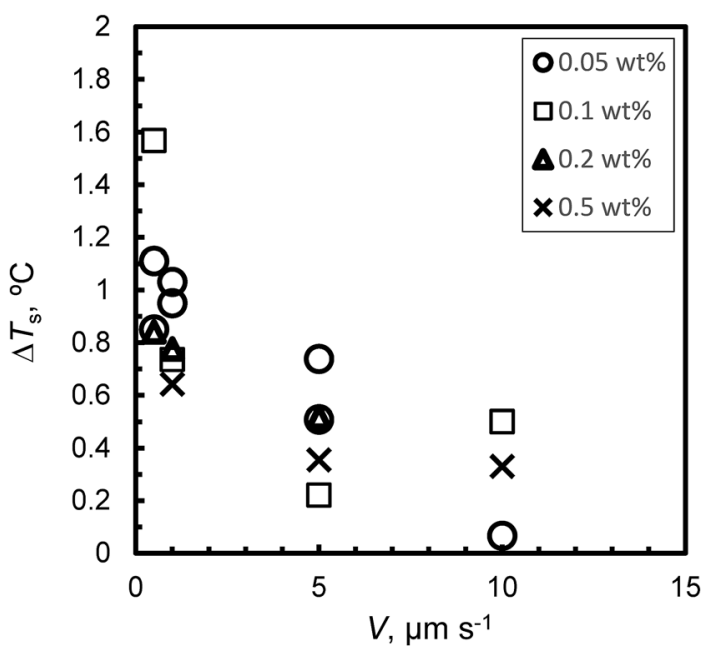

Fig. 4 The relationship between $V$ and degree of superheating, $\Delta T_{\mathrm{s}}$, of the initial interface. where $\Delta T_{\mathrm{s}}$ is the degree of superheating of the initial interface at $t=0 \mathrm{~min} . \Delta T_{\mathrm{s}}$ may be influenced by the melting time, the type of KHI added and the KHI concentration.

An exact comparison of calculated values and direct temperature measurements also reveals that $V$ slightly affects the $G$ of the sample cell. Therefore, to be more precise, Formula (2) should be modified to account for the motion of the sample cell.

$$
\Delta T=G\left(\Delta x-x_{\mathrm{T}}\right)-\Delta T_{\mathrm{s}}
$$

In Formula (3), $x_{\mathrm{T}}$ is the distance the isotherm is shifted towards the cold side because of the cell motion. $x_{\mathrm{T}}$ should increase with increasing $V$. To evaluate the interface temperature using Formula (3), $x_{\mathrm{T}}$ and $\Delta T_{\mathrm{S}}$ must be determined empirically for each KHI. Formula (1) can only be applied under experimental conditions with lower range values of $V$ and $\mathrm{KHI}$ additives with a small superheating effect.

In the case where no additive solution is present (THF-water solution), $\Delta T_{\mathrm{s}}=0$. Formula (3) becomes Formula (4).

$$
x_{\mathrm{T}}=\Delta x-\frac{\Delta T}{G}
$$
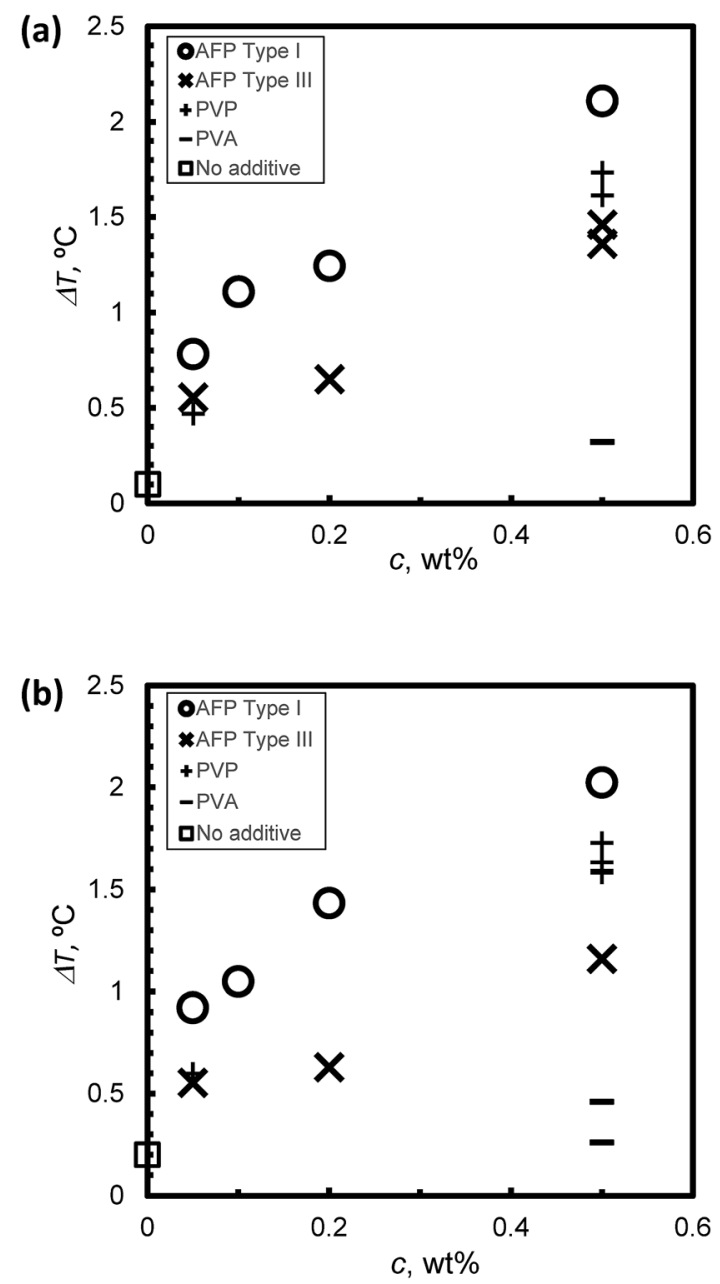

Fig. 5 The relationship between $\mathrm{KHI}$ concentration, $c$ and the degree of super cooling, $\Delta T$, under steady state conditions at (a) $V=1 \mu \mathrm{m} \mathrm{s}^{-1}$ and (b) $V=5 \mu \mathrm{m} \mathrm{s}^{-1}$. 

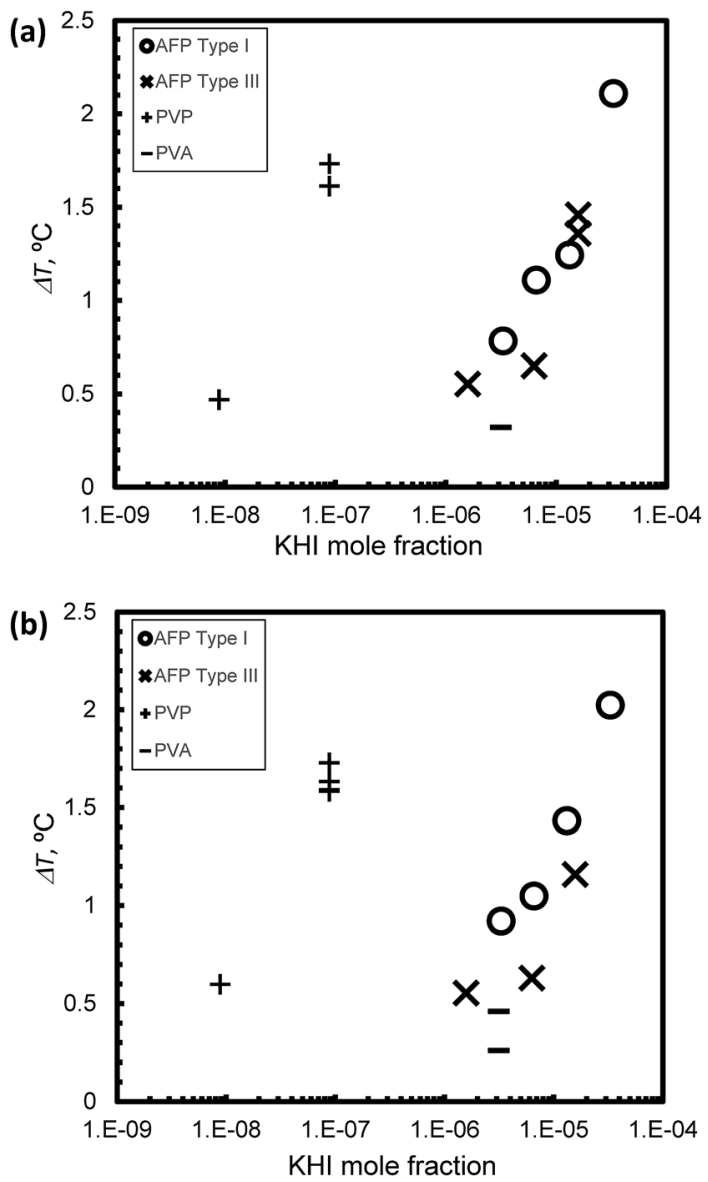

Fig. 6 The relationship between $\mathrm{KHI}$ mole fraction and degree of super cooling, $\Delta T$, under steady state conditions at (a) $V=1 \mu \mathrm{m} \mathrm{s}^{-1}$ and (b) $V=5 \mu \mathrm{m} \mathrm{s}^{-1}$.

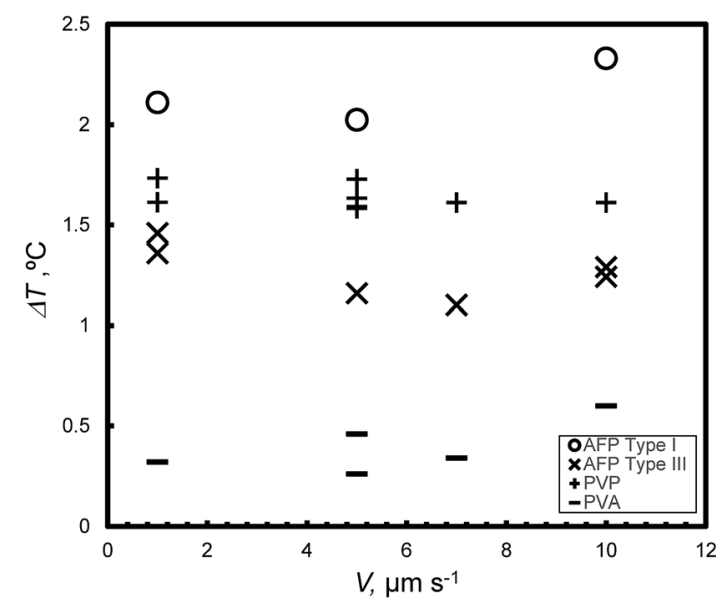

Fig. 7 The relationship between $V$ and the degree of super cooling, $\Delta T$, under steady state conditions at $c=0.5 \mathrm{wt} \%$.

Fig. 3 shows the relationship between $x_{\mathrm{T}}$ and $V$ of the THF hydrate (no additive). $x_{\mathrm{T}}$ is obtained by Formula (4) and the measured values of $\Delta x, \Delta T$ and $G$. By carrying out a linear fit, $x_{\mathrm{T}}$ $=0.14 \mathrm{~V}$ is obtained.
Fig. 4 shows the relationship between $\Delta T_{\mathrm{s}}$ and $V$ for Type I AFP; $\Delta T_{\mathrm{s}}$ is not dependent on $c$. For the same experimental condition as for $\Delta T_{\mathrm{s}}=0$, a variation of approximately $0.3{ }^{\circ} \mathrm{C}$ is found when Type I AFP is included. Therefore, the temperature of the growth interface is measured directly using a thermocouple to avoid this error.

Fig. $5 \mathrm{a}$ and $\mathrm{b}$ summarize the relation between the $\mathrm{KHI}$ concentration $c$ and the degree of supercooling $\Delta T$ under steady state conditions at (a) $V=1 \mu \mathrm{m} \mathrm{s}^{-1}$ and (b) $V=5 \mu \mathrm{m} \mathrm{s}^{-1}$, respectively. $\Delta T$ increased along with $c$ in all cases. In the case of $c$ $=0.5 \mathrm{wt} \%$, the $\Delta T$ of Type I AFP exhibits the best performance. The inhibition performance of PVP is second best followed by Type III AFP; PVA performs weakly. The result of PVA is consistent with that in ref. 5; this study reported that PVA is not an inhibitor.

(a)

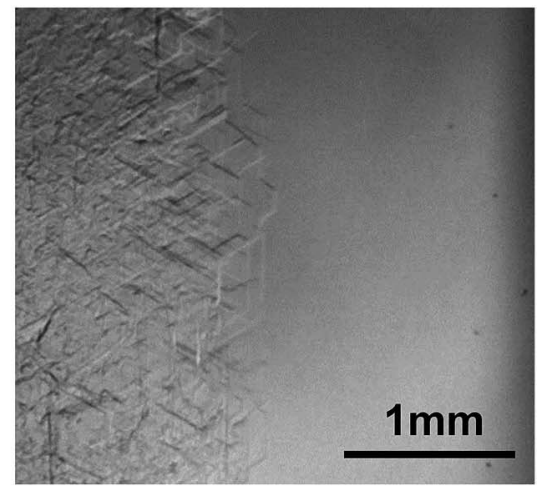

\section{(b)}

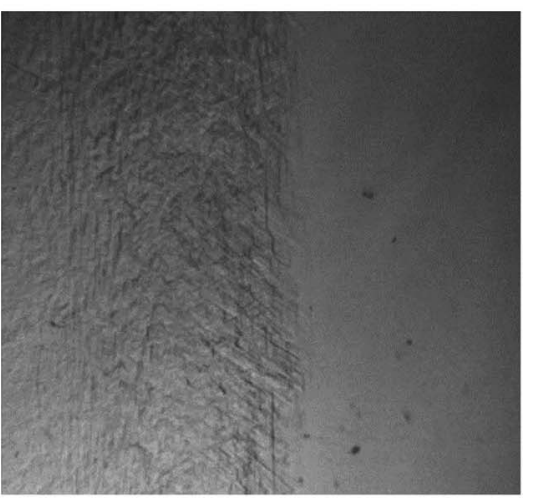

(c)

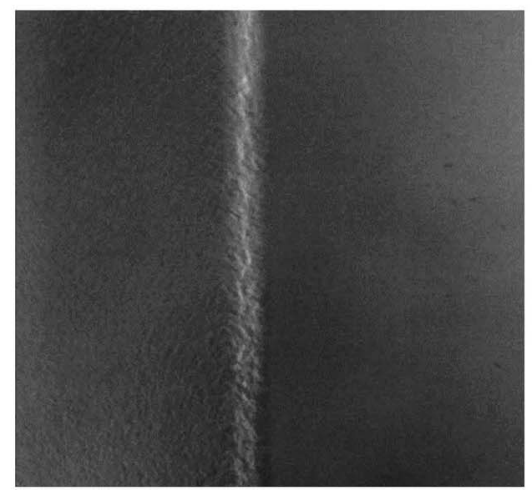

Fig. 8 Steady state images of the hydrate growth interface with the additive Type I AFP at concentrations of $c=$ (a) $0.05 \mathrm{wt} \%$, (b) $0.2 \mathrm{wt} \%$ and (c) $0.5 \mathrm{wt} \%$ for $V=1 \mu \mathrm{m} \mathrm{s}^{-1}$. 
Fig. 6(a) and (b) summarize the relationship between KHI mole fraction and degree of supercooling, $\Delta T$, under steady state conditions at $V=1 \mu \mathrm{m} \mathrm{s}^{-1}$ and $V=5 \mu \mathrm{m} \mathrm{s}^{-1}$, respectively. The KHI mole fraction of PVP was less than 2 orders of magnitude as compared to AFPs. This is caused by the molecular weight of PVP that is larger than AFPs. The KHI mole fraction of PVP is extremely low as compared to AFPs; however, the $\Delta T$ of PVP is of the same order magnitude as $\Delta T$ of the AFPs. This result suggests that a single molecule of PVP has multiple adsorption sites on the hydrate surface. Thus, to clarify the KHI inhibition mechanism, it is important to determine the number of adsorption sites of a single $\mathrm{KHI}$ molecule.

(a)

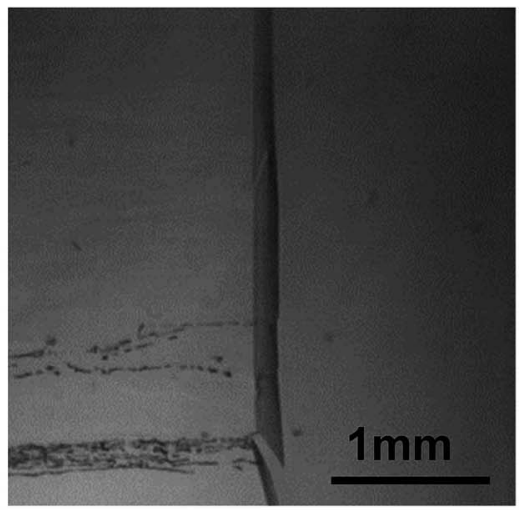

(b)

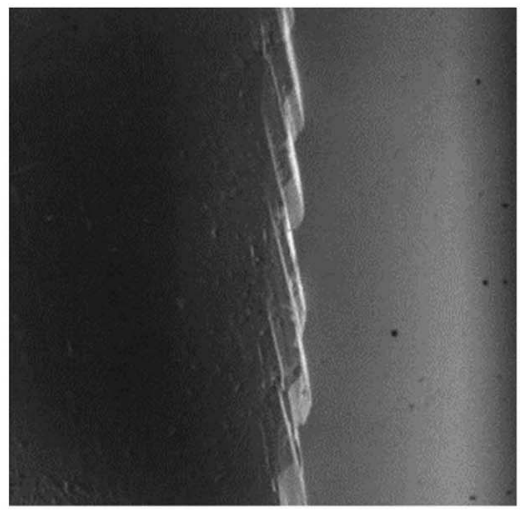

(c)

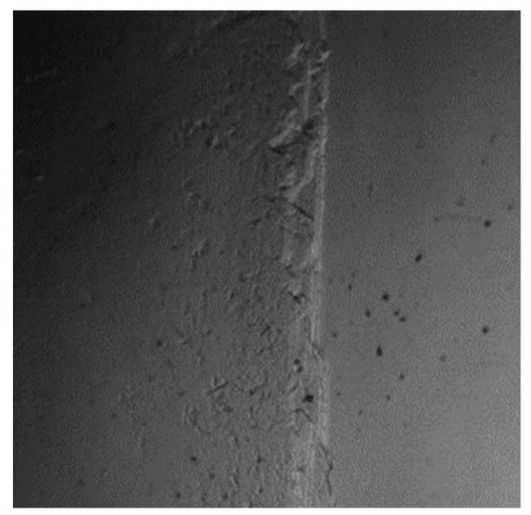

Fig. 9 Steady state images of the hydrate growth interface with the additive Type III AFP at concentrations of $c=$ (a) 0.05 wt\%, (b) 0.2 wt $\%$ and (c) $0.5 \mathrm{wt} \%$ for $V=1 \mu \mathrm{m} \mathrm{s}^{-1}$.
The KHI inhibitor performance is summarized by the following ranking: Type I AFP > PVP > Type III AFP > PVA. The result of TYPE I AFP is consistent with that in ref. 19.

Fig. 7 presents the weak dependence of the degree of supercooling $(\Delta T)$ on $V$ under steady state conditions at $c=$ $0.5 \mathrm{wt} \%$; for each KHI, the $\Delta T$ is similar for different values of $V$.

Fig. 8 shows images of the hydrate growth interface at steady state for different Type I AFP concentrations; $c=$ (a) $0.05 \mathrm{wt} \%$, (b) $0.2 \mathrm{wt} \%$ and (c) $0.5 \mathrm{wt} \%$ for $V=1 \mu \mathrm{m} \mathrm{s}^{-1}$. At $c=0.05 \mathrm{wt} \%$, a hexagonal plate-like crystal forms across the whole growth interface. At $c=0.2 \mathrm{wt} \%$, a relatively small hexagonal plate forms at the growth interface. At $c=0.5 \mathrm{wt} \%$, the shape of the growth interface is relatively flat. Fig. 9 shows images of the hydrate growth interface at steady state for different concentrations of Type III AFP; $c=$ (a) $0.05 \mathrm{wt} \%$, (b) $0.2 \mathrm{wt} \%$ and (c) $0.5 \mathrm{wt} \%$ for $V=1 \mu \mathrm{m} \mathrm{s}^{-1}$. At $c=0.05 \mathrm{wt} \%$, flat-plate crystals form. At $c=0.2 \mathrm{wt} \%$, a concave-convex pattern appears at the interface, and at $c=0.5 \mathrm{wt} \%$, many concave-convex pattern crystals are found at the growth interface. Fig. 10 shows images of the hydrate growth interface at steady state with $V=$ (a) 0.5 $\mu \mathrm{m} \mathrm{s}^{-1}$ and (b) $10 \mu \mathrm{m} \mathrm{s}^{-1}$ for added Type I AFP concentration $c$ $=0.05 \mathrm{wt} \%$. At $V=0.5 \mu \mathrm{m} \mathrm{s}^{-1}$, a flat-plate hexagonal crystal forms. At $V=10 \mu \mathrm{m} \mathrm{s}^{-1}$, the concave-convex pattern forms. Fig. 11 shows images of the hydrate growth interface at steady
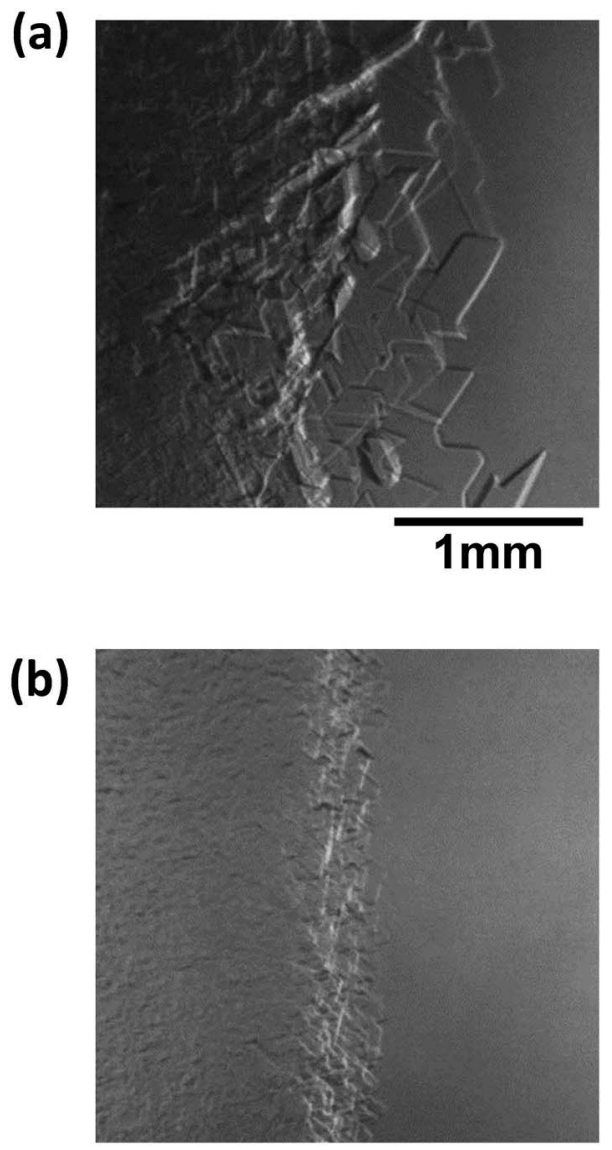

Fig. 10 Steady state images of the hydrate growth interface with $V=$ (a) $0.5 \mu \mathrm{m} \mathrm{s}^{-1}$ and (b) $10 \mu \mathrm{m} \mathrm{s}^{-1}$ for additive Type I AFP at a concentration of $c=0.05 \mathrm{wt} \%$. 


\section{(a)}

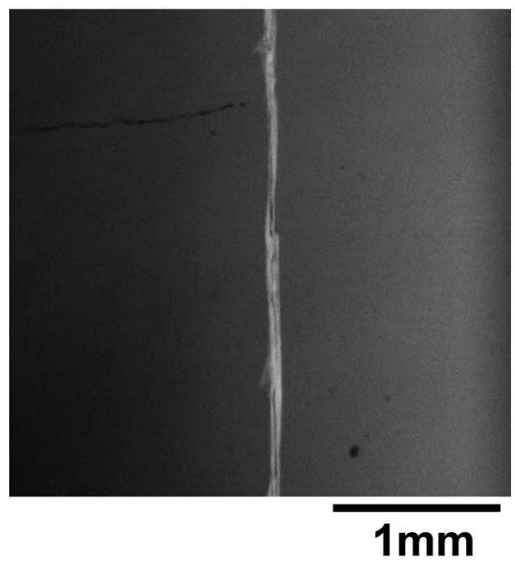

(b)

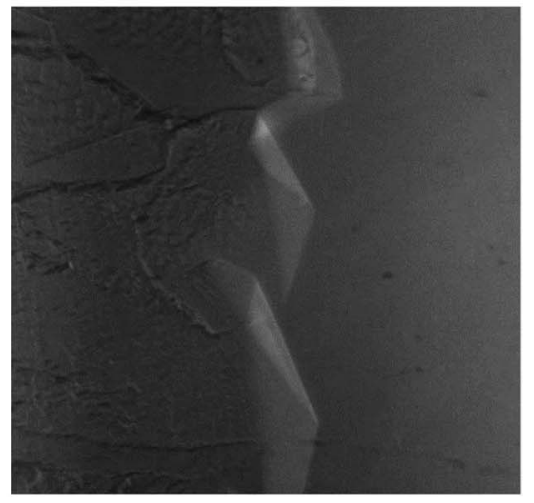

Fig. 11 Steady state images of the hydrate growth interface for $V=(a)$ $0.5 \mu \mathrm{m} \mathrm{s}^{-1}$ and (b) $10 \mu \mathrm{m} \mathrm{s}^{-1}$ for the additive Type III AFP with concentration of $c=0.05 \mathrm{wt} \%$.

state with $V=$ (a) $0.5 \mu \mathrm{m} \mathrm{s}^{-1}$ and (b) $10 \mu \mathrm{m} \mathrm{s}^{-1}$ for added Type III AFP concentration $c=0.05 \mathrm{wt} \%$. At $0.5 \mu \mathrm{m} \mathrm{s}^{-1}$, the flat-plate crystal forms, and at $V=10 \mu \mathrm{m} \mathrm{s}^{-1}$, the concave-convex pattern forms.

Here, Type I AFP is more effective than Type III AFP. This seems to be related to a difference in how the AFP influences the hydrate crystal surface structure. Depending on its concentration, the presence of Type I AFP changes the crystal morphology drastically. Conversely, at all concentrations of Type III AFP, the same crystal morphology is found. This result suggests that crystal morphology is an important factor in determining KHI performance.

All KHIs in this study finely destabilized the growth interface. The many crystal boundary might entrap KHIs The flat $\Delta T$ dependence on $V$ as shown in Fig. 7 likely results from such entrapping. The weak $\Delta T$ dependence on $V$ is expected to lead to consistent on-site KHI performance.

\section{Conclusions}

The kinetic inhibition performance of KHIs (Type I AFP, Type III AFP, PVA and PVP) for unidirectional THF hydrate crystal growth was evaluated. Supercooling at the growth interface was affected by the chemical species of the inhibitor and its concentration. The degree of supercooling caused by the AFP tends to be overestimated due to superheating, as also reported by Celik et al. Therefore, we measured the temperature of the growth interface directly using a thermocouple to avoid this overestimation.

The rank of kinetic inhibition performance of the studied compounds was found to be Type I AFP > PVP > Type III AFP > PVA.

Type I AFP changed the morphology of the THF hydrate crystal drastically depending on its concentration. Type III AFP did not show this effect. The difference in the effectiveness of these AFPs shows that their influence on the crystal morphology is an important factor for determining their antifreeze performance.

\section{Conflicts of interest}

There are no conflicts to declare.

\section{Acknowledgements}

The authors would like to thank Norio Tenma for fruitful suggestions on this study.

\section{Notes and references}

1 E. D. Sloan and C. A. Koh, Clathrate Hydrates of Natural Gases, 3rd edn, CRC Press, Boca Raton, Fla, 2007.

2 E. G. Hammerschmidt, Ind. Eng. Chem., 1934, 26, 851.

3 M. A. Kelland, Energy Fuels, 2006, 20, 825.

4 J. P. Lederhos, J. P. Long, A. Sum, R. L. Christiansen and E. D. Sloan, Chem. Eng. Sci., 1996, 51, 1221.

5 R. Larsen, C. A. Knight and E. D. Sloan, Fluid Phase Equilib., 1998, 150, 353.

6 R. Anderson, H. Mozaffar and B. Tohidi, Proceedings of the 7th International Conference on Gas Hydrates, Edinburgh, Scotland, UK, 2011.

7 P. C. Chua and M. A. Kelland, Energy Fuels, 2012, 26, 1160.

8 M. A. Kelland, Adv. Mater. Sci. Res., 2011, 8, 171.

9 D. A. Vorontsov, G. Sazaki, E. K. Titaeva, E. L. Kim, M. BayerGiraldi and Y. Furukawa, Cryst. Growth Des., 2018, 18, 2563.

10 J. G. Duman and A. L. Devries, Nature, 1974, 247, 237.

11 D. S. C. Yang, M. Sax, A. Chakrabartty and C. L. Hew, Nature, 1988, 333, 232.

12 S. Mahatabuddin, Y. Hanada, Y. Nishimiya, A. Miura, H. Kondo, P. L. Davies and S. Tsuda, Sci. Rep., 2017, 7, 42501.

13 J. Baardsnes and P. L. Davies, Trends Biochem. Sci., 2001, 26, 468.

14 F. D. Sonnichsen, B. D. Sykes, H. Chao and P. L. Davies, Science, 1993, 259, 1154.

15 A. A. Antson, D. J. Smith, D. I. Roper, S. Lewis, L. S. Caves, C. S. Verma, S. L. Buckley, P. J. Lillford and R. E. Hubbard, J. Mol. Biol., 2001, 305, 875.

16 H. Zeng, L. D. Wilson, V. K. Walker and J. A. Ripmeester, J. Am. Chem. Soc., 2006, 128, 2844.

17 H. Zeng, I. L. Moudrakovski, J. A. Ripmeester and V. K. Walker, AIChE J., 2006, 52, 3304.

18 N. Daraboina, J. Ripmeester, V. K. Walker and P. Englezos, Energy Fuels, 2011, 25, 4392-4397. 
19 N. Daraboina, P. Linga, J. Ripmeester, V. K. Walker and P. Englezos, Energy Fuels, 2011, 25, 4384.

20 N. Daraboina, J. Ripmeester, V. K. Walker and P. Englezos, Energy Fuels, 2011, 25, 4398.

21 T. Inada and P. R. Modak, Chem. Eng. Sci., 2006, 61, 3149.

22 H. Y. Wang, T. Inada, K. Funakoshi and S. S. Lu, Cryobiology, 2009, 59, 83.

23 C. Budke and T. Koop, ChemPhysChem, 2006, 7, 2601.

24 T. Inada and S. S. Lu, Cryst. Growth Des., 2003, 3, 747.

25 J. Du, Y. Wang, X. Lang and S. Fan, Energy Fuels, 2011, 25, 3204.
26 J. R. DuQuesnay, M. C. Posada and J. G. Beltran, Fluid Phase Equilib., 2016, 413, 148.

27 L. U. Udegbunam, J. R. DuQuesnay, L. Osorio, V. K. Walker and J. G. Beltran, J. Chem. Thermodyn., 2018, 117, 155.

28 M. Muraoka, N. Susuki and Y. Yamamoto, $R S C A d v$., 2016, 6, 63880.

29 Y. Celik, L. A. Graham, Y. F. Mok, M. Bar, P. L. Davies and I. Braslavsky, Proc. Natl. Acad. Sci. U. S. A., 2010, 107, 5423. 30 C. A. Knight and A. L. DeVries, Science, 1989, 245, 505. 